\title{
Assessment of psychiatric changes in C9ORF72 frontotemporal dementia
}

\author{
Michael Hornberger ${ }^{1,2,3 *}$ \\ See related research by Downey et al., http://alzres.com/content/4/5/42
}

\begin{abstract}
Recent neuroimaging evidence highlights cerebellar atrophy as one feature of frontotemporal dementia (FTD) with C9ORF72 mutation. Interestingly, C9ORF72 patients do not present with classic cerebellar symptoms, such as ataxia, but have instead a higher incidence of psychiatric changes compared to sporadic FTD. To date there exists no objective tool to assess such psychiatric changes due to cerebellar dysfunction. In the previous edition of Alzheimer's Research \& Therapy, Downey and colleagues present a novel task, including a new apparatus, that targets such psychiatric disturbances. In the task participants are required to make self-other attributions, which have been shown to be dependent on the cerebellum in functional neuroimaging in healthy subjects. The data Downey and colleagues present on a case of C9ORF72 compared to four age-matched controls reveal that the patient shows impaired judgement only for other induced actions. These findings highlight the sensitivity of such a simple task to tap into potential cerebellar dysfunction in C9ORF72. Future studies are needed to now to determine whether this task is mediated solely via the cerebellum and is disease specific to C9ORF72. Nevertheless, this study is an important first step in the development of cerebellar-specific tasks tapping into psychiatric dysfunction, which will inform future diagnosis and disease management of patients with cerebellar dysfunction, and in particular C9ORF72.
\end{abstract}

The recent discovery of a new genetic mutation (C9ORF72) in frontotemporal dementia (FTD) [1-3] has triggered a plethora of new research into this disease. Of particular interest are which clinical, cognitive and

*Correspondence: m.hornberger@neura.edu.au

'Neuroscience Research Australia, Sydney, NSW 2031, Australia

Full list of author information is available at the end of the article neuroimaging signatures are potential in vivo biomarkers for the C9ORF72 mutation.

On a neuroimaging level, C9ORF72 cases have been found to have substantially more atrophy in the cerebellum compared to sporadic FTD patients and agematched healthy controls $[4,5]$. This finding suggested that cerebellar atrophy and its concomitant dysfunction could be a potential biomarker for a C9ORF72 mutation. However, patients with the C9ORF72 mutation do not show classic cerebellar dysfunction symptoms, such as ataxia, which presents with incoordination of balance, gait, extremity and eye movements, as well as dysarthria. This paradox highlights how little is known of the functions of the cerebellum, a brain structure that comprises nearly $10 \%$ of brain volume and contains 3.5 times more neurons than the whole neocortex. Still, reports of cerebellar patients also often describe impairments of intellectual functioning and emotional or psychiatric disturbances. This has been further corroborated by recent evidence suggesting that cerebellar patients can show cognitive and affective deficits, in particular executive dysfunction, impaired spatial memory, and personality changes characterised by disinhibited or inappropriate behaviour, with some cases having clear psychotic features [6]. Such psychiatric disturbances due to cerebellar dysfunction dovetail nicely with the finding that C9ORF72 cases show a higher incidence of psychiatric features compared to sporadic FTD cases [7]. Unfortunately, however, to date there is a dearth of tools that can investigate such cognitive or psychiatric cerebellar dysfunction, which could have the potential to be in vivo functional biomarkers for C9ORF72 without the need for expensive neuroimaging or genetic analyses.

In the previous edition of Alzheimer's Research $\mathcal{E}$ Therapy, Downey and colleagues [1] present a novel task, including a new apparatus, that addresses exactly this issue by targeting specifically psychiatric symptoms putatively due to cerebellar dysfunction. The design of this novel test is based on the rationale that patients with psychiatric disorders often show problems in dissociating self-generated actions from actions generated by others [8] and that the cerebellum is in general involved in 
self-other action attributions [9]. To assess such an effect of self-other attributions, Downey and colleagues created a novel experimental apparatus. In brief, the apparatus, which can be seen in Figure 2 of the publication [1], consists of a metal rod, which can be rotated freely via a handle on one side. Attached to the metal rod is a paintbrush that can be adjusted so that it can brush against the participants hand when the rod is rotated. Importantly, the rod can also be moved horizontally so that only in some trials the brush would touch the hand (self condition) when the participant used his other hand to move the handle, while in other trials it would not touch the hand (other condition). In the other condition, the experimenter instead brushed the participants hand with an identical paintbrush. During the whole experiment the participants where blindfolded and had to decide in a self-paced manner whether the sensory stimulus was delivered by their own actions or via the experimenter. The results of Downey and colleagues show a clear dissociation of self-other attribution, with the C9ORF72 patient being only impaired for the other condition compared to four age-matched controls.

The findings of Downey and colleagues are an important first step to assessing psychiatric dysfunction in a more objective way, which has clear clinical relevance. In particular, assessment of neuropsychiatric features still remains largely subjective and is dependent on many factors, including carer perceptiveness as well as the presentation of the patient at the clinic. Thus, an objective test that can corroborate carer and clinical assessments of psychiatric changes would be a very valuable tool, especially in C9ORF72 cases. Critically, follow-up studies employing this task need to confirm now whether this novel measure is indeed tapping into cerebellar dysfunction and has therefore a certain regional specificity. In particular, the differentiation from prefrontal changes will be important, as the cerebellum and prefrontal cortex share strong cerebro-cerebellar white matter connections and self-other judgment deficits in the form of lack of disease insight, a highly prevalent symptom in FTD, have been shown to be largely prefrontal cortex dependent $[10,11]$. Similarly, it would be important to contrast C9ORF72 cases against sporadic FTD cases to determine the sensitivity and specificity of the novel task effect across FTD patient groups, which would inform the clinical diagnosis criteria for C9ORF72. Finally, covarying the degree of psychiatric disturbances against the level of cerebellar degeneration would provide further compelling evidence that these symptoms are indeed critically dependent on cerebellar dysfunction.

\section{Conclusion}

Taken together, the novel tool introduced by Downey and colleagues as well as their findings in a case with a
C9ORF72 mutation are very promising and provide an important stepping stone towards objective assessment of neuropsychiatric and cognitive changes due to cerebellar dysfunction in neurodegeneration. In turn, the development of such novel tools will potentially not only improve the diagnosis of patients with cerebellar dysfunction, such as C9ORF72 cases, but will also allow improved disease management to address the psychiatric changes. Finally, this will hopefully pave the way to elucidate the contributions of the cerebellum towards behaviour and cognition more generally, which clearly has been neglected for far too long.

\section{Abbreviations}

FTD, frontotemporal dementia.

\section{Competing interests}

The author declares that he has no competing interests.

\section{Acknowledgments}

$\mathrm{MH}$ is supported by an Australian Research Council Research Fellowship (DP110104202).

\section{Author details}

${ }^{1}$ Neuroscience Research Australia, Sydney, NSW 2031, Australia. ${ }^{2}$ Faculty of Medicine, University of New South Wales, Sydney, NSW 2031, Australia. ${ }^{3}$ ARC Centre of Excellence for Cognition and its Disorders, Sydney, NSW 2031, Australia.

Published: 24 December 2012

\section{References}

1. Downey LE, Mahoney CJ, Rossor MN, Crutch SJ, Warren JD: Impaired selfother differentiation in frontotemporal dementia due to the C9ORF72 expansion. Alzheimers Res Ther 2012, 4:42.

2. DeJesus-Hernandez M, Mackenzie IR, Boeve BF, Boxer AL, Baker M, Rutherford NJ, Nicholson AM, Finch NA, Flynn H, Adamson J, Kouri N, Wojtas A, Sengdy P, Hsiung GY, Karydas A, Seeley WW, Josephs KA, Coppola G, Geschwind DH, Wszolek ZK, Feldman H, Knopman DS, Petersen RC, Miller BL, Dickson DW, Boylan KB, Graff-Radford NR, Rademakers R: Expanded GGGGCC hexanucleotide repeat in noncoding region of C9ORF72 causes chromosome 9p-linked FTD and ALS. Neuron 2011, 72:245-256.

3. Renton AE, Majounie E, Waite A, Simón-Sánchez J, Rollinson S, Gibbs JR, Schymick JC, Laaksovirta H, van Swieten JC, Myllykangas L, Kalimo H, Paetau A, Abramzon Y, Remes AM, Kaganovich A, Scholz SW, Duckworth J, Ding J, Harmer DW, Hernandez DG, Johnson JO, Mok K, Ryten M, Trabzuni D, Guerreiro RJ, Orrell RW, Neal J, Murray A, Pearson J, Jansen IE, et al.: A hexanucleotide repeat expansion in C9ORF72 is the cause of chromosome 9p21-linked ALS-FTD. Neuron 2011, 72:257-268.

4. Whitwell JL, Weigand SD, Boeve BF, Senjem ML, Gunter JL, DeJesusHernandez M, Rutherford NJ, Baker M, Knopman DS, Wszolek ZK, Parisi JE, Dickson DW, Petersen RC, Rademakers R, Jack CR Jr, Josephs KA: Neuroimaging signatures of frontotemporal dementia genetics: C9ORF72, tau, progranulin and sporadics. Brain 2012, 135:794-806.

5. Mahoney CJ, Beck J, Rohrer JD, Lashley T, Mok K, Shakespeare T, Yeatman T, Warrington EK, Schott JM, Fox NC, Rossor MN, Hardy J, Collinge J, Revesz T, Mead S, Warren JD: Frontotemporal dementia with the C9ORF72 hexanucleotide repeat expansion: clinical, neuroanatomical and neuropathological features. Brain 2012, 135:736-750.

6. Schmahmann JD, Caplan D: Cognition, emotion and the cerebellum. Brain 2006, 129:290-292

7. Snowden JS, Rollinson S, Thompson JC, Harris JM, Stopford CL, Richardson AM, Jones M, Gerhard A, Davidson YS, Robinson A, Gibbons L, Hu Q, DuPlessis D, Neary D, Mann DM, Pickering-Brown SM: Distinct clinical and pathological characteristics of frontotemporal dementia associated with C9ORF72 mutations. Brain 2012, 135:693-708.

8. Franck N, Farrer C, Georgieff N, Marie-Cardine M, Daléry J, d'Amato T, Jeannerod M: Defective recognition of one's own actions in patients with 
schizophrenia. Am J Psychiatry 2001, 158:454-459.

9. Frith CD, Blakemore SJ, Wolpert DM: Abnormalities in the awareness and control of action. Philos Trans R Soc Lond B Biol Sci 2000, 355:1771-1788.

10. Hornberger M, Yew B, Gilardoni S, Mioshi E, Gleichgerrcht E, Manes F, Hodges JR: Ventromedial-frontopolar prefrontal cortex atrophycorrelates with insight loss in frontotemporal dementia and Alzheimer's disease. Hum Brain Mapp. doi: 10.1002/hbm.22200.

11. MCMurtray AM, Chen AK, Shapira JS, Chow TW, Mishkin F, Miller BL, Mendez
MF: Variations in regional SPECT hypoperfusion and clinical features in frontotemporal dementia. Neurology 2006, 66:517-522.

doi:10.1186/alzrt152

Cite this article as: Hornberger M: Assessment of psychiatric changes in C9ORF72 frontotemporal dementia. Alzheimer's Research \& Therapy 2012,

4:49. 